\title{
A DIMENSÃO OCUPACIONAL DO SETOR DE ATENDIMENTO À SAÚDE NO BRASIL
}

THE OCCUPATIONAL DIMENSION OF THE HEALTH CARE SECTOR IN BRAZIL

\author{
Claudio Salvadori Dedecca 1 \\ Eliane Navarro Rosandiski 2 \\ Marcelo Soares de Carvalho 3 \\ Carolina Veríssimo Barbieri 4
}

Resumo Este artigo propõe uma metodologia para estimar a dimensão ocupacional do setor de atendimento à saúde e destaca o papel fundamental deste setor para a geração de ocupação e a elevação do perfil de qualificação do mercado de trabalho nacional. A análise parte do pressuposto que o setor de atendimento à saúde, como os demais segmentos vinculados à política social, tem o trabalho como elemento central da organização de sua atividade. Embora as novas tecnologias auxiliem a atividade no setor, possibilitam apenas uma substituição limitada do recurso humano. Assim, parte importante dos riscos inerentes aos atendimentos não é passível de reversão, devendo ser prevenidos sistematicamente, o que exige uma política recorrente de qualificação e regulamentação dos recursos humanos em saúde. A análise toma por base os dados do Censo Demográfico de 2000 e da Relação Anual de Informações Sociais para 2001.

Palavras-chave emprego; política social; regulamentação.
Abstract This article proposes a methodology to estimate the occupational dimension of the Health Care sector and emphasizes the essential role played by this sector in the generation of jobs and in the improvement of the qualification profile of the Brazilian labour market. The assumption underlying the analysis is that, for the health care sector, as for the other segments connected with social policy, labour is the central element in the organization of their activities. Although the new technologies may help, they can only replace the human resources in a very limited number of activities. Since an important part of the risks inherent to care cannot be reversed, and must, therefore, be systematically prevented, health care requires the constant elaboration of policies concerned with the qualification and regulation of human resources in health. The analysis is based on data from the 2000 Demographic Census and from the Annual Relation of Social Information for the year 2001. Key words jobs; social policy; regulation. 


\section{Introdução}

Este artigo tem como objetivo apresentar uma metodologia e seus resultados para mensuração da ocupação gerada pela política de atendimento à saúde 5 . A iniciativa conta com pouca tradição não só no Brasil, mas também nos países desenvolvidos. A literatura sobre o assunto é escassa (Engel, 1999; Dedecca, Proni e Moreto, 2001), restringindo-se em grande medida ao tema da gestão dos recursos humanos em saúde (Poz, Pierantoni e Varella, 1997; Nogueira e Santana, 2000), isto é, da administração das funções de medicina e enfermagem no processo de trabalho da política de atendimento à saúde.

Além da maioria dos estudos estarem restritos às questões mais administrativas, não se encontram maiores iniciativas de mensurar o impacto do gasto da política de saúde na geração de postos de trabalho. Normalmente, a avaliação desse tipo de impacto circunscreve-se aos efeitos sobre o bemestar da população, que deve, sem dúvida, continuar sendo o principal objetivo da política de atendimento à saúde. Entretanto, a intensidade com que essa política pode alcançar tal objetivo depende das características da organização de seu mercado específico de trabalho.

Neste artigo, discute-se, inicialmente, o que poderia ser denominado de mercado de trabalho específico do setor saúde. Em seguida, apresenta-se uma metodologia de mensuração da ocupação induzida pelo gasto da política de saúde. A partir desse procedimento, faz-se a estimativa do total de ocupação, diferenciando-a entre os segmentos 'nuclear', 'afim' e 'demais', segundo a vinculação com a atividade-fim do setor. Conhecida a extensão da política ocupacional, analisa-se a parcela de ocupação vinculada à atividadefim. A partir daí, discutem-se as ocupações nucleares buscando, com essa reflexão, apresentar algumas observações relevantes para a discussão sobre trabalho no setor saúde brasileiro.

\section{O mercado de trabalho para atividades de atendimento do setor saúde}

Nos últimos anos, têm crescido as indagações sobre o que seria o mercado de trabalho do setor saúde. As iniciativas do Ministério da Saúde de avançar a regulamentação e promover a qualificação dos ocupados em funções de enfermagem tornam explícita a importância do tema e as dificuldades em debatê-lo. Também a reorganização e as novas iniciativas da política de atendimento à saúde, ao fomentarem a discussão sobre a qualidade dos serviços prestados, induzem o próprio debate sobre o mercado de trabalho do setor.

O mercado de trabalho do setor de atendimento à saúde apresenta características específicas. Para a grande maioria daqueles que participam do mercado de trabalho em geral, as exigências de qualificação são, em regra, bas- 
tante genéricas, sendo, inclusive, boa parte dela desenvolvida no exercício da função. Os economistas e sociólogos denominam esse processo de job training. Mesmo em funções mais qualificadas, o processo de trabalho produz características específicas, de tal modo que certas habilidades são perdidas quando a pessoa sai de uma empresa, necessitando, muitas vezes, passar por um novo período de adaptação às novas condições de realização de sua função.

O mercado de trabalho do setor saúde se diferencia dessa situação mais geral, havendo funções associadas diretamente a certas categorias ocupacionais. Cabe esclarecer que há profissionais responsáveis pelas atividadesfim e outros que cumprem o papel de apoio a esse tipo de atividade.

O cozinheiro, o motorista, o segurança que trabalham nos hospitais pertencem ao setor saúde, mas realizam tarefas de apoio, e suas qualificações são adquiridas, normalmente, no mercado geral de trabalho. Também se enquadra nessa situação um outro conjunto de ocupações do setor que são criadas indiretamente. Estão aí incluídas, por exemplo, ocupações da indústria farmacêutica e de material cirúrgico ou, mais especificamente, ocupações como a de piloto de helicóptero da empresa que arrenda regularmente equipamentos para uma organização do setor saúde.

O mesmo não se pode dizer das funções diretamente associadas à atividade-fim, como as do médico, do enfermeiro diplomado, do técnico de enfermagem, do psicólogo, do radiologista, do laboratorista. O exercício dessas funções requer uma qualificação reconhecida por órgãos públicos. Não é possível a qualquer pessoa concorrer a um posto de médico em um hospital. É necessário que ela possua a qualificação específica atestada publicamente. Por esse motivo, conforma-se um conjunto de profissões (exercidas no mercado de trabalho do setor) que não têm suas funções regulamentadas diretamente pelas partes que estabelecem o contrato de trabalho. Ou seja, para este conjunto de ocupações, as características da função não são definidas a partir das características particulares do processo de trabalho de um determinado hospital. Isto demonstra que, ao contrário do mercado de trabalho em geral, parcela preponderante das características das funções nucleares da área de saúde é independente do local em que se realiza. O determinante principal dessa regulamentação da função, que provoca a sua consolidação como profissão, é o caráter irreversível do risco inerente aos serviços prestados pelo setor - que, neste caso, abrange tanto o cliente como o prestador do serviço. A regulamentação busca reduzir a exposição do paciente e dos profissionais ao risco.

Podem-se tomar os exemplos de dois pacientes atendidos por dois oftalmologistas. O primeiro deles recebe uma receita de óculos com grau incorreto. Ele pode voltar ao médico e o erro ser corrigido ou pode buscar um outro profissional, acreditando ser mais seguro. As conseqüências produzidas pelo erro médico podem ser facilmente corrigidas, com um ônus relativamente baixo. 
Na outra situação, o paciente passou por uma operação de catarata que, em razão de um erro cirúrgico, acarretou a perda da visão. Neste caso, uma volta ao médico ou a busca de um outro profissional não lhe permitirá reverter o resultado desfavorável. O mesmo poderia se dizer de uma pessoa hemofílica que é contaminada pelo vírus HIV em uma transfusão sangüínea. O resultado não somente é irreversível, como coloca em risco a própria vida do paciente.

É impossível eliminar totalmente esses e outros riscos inerentes à prestação do serviço de atendimento à saúde. Contudo, é inegável ser possível diminuir a probabilidade de ocorrência, regulando as diversas funções voltadas para a atividade-fim através do estabelecimento das profissões e da regulamentação de procedimentos. Essa não é uma característica exclusiva do setor saúde. Vale destacar que os mercados de trabalho dos setores de educação e transporte aéreo são também regulamentados.

A ação pública de regulamentação das funções do setor gera outras particularidades. Em geral, os custos não podem servir para balizar a tomada de decisões. A necessidade de minimizar riscos pode ser incompatível com a obtenção de custos mais baixos. Muitas vezes, faz-se necessário adotar certos procedimentos que, na maioria dos casos, não precisariam ser utilizados. Por exemplo, é preciso manter um radiologista em plantão, mesmo que seus serviços sejam demandados por poucas horas ao longo do dia. Isso, claramente, provoca um aumento dos custos das atividades realizadas pelo setor. Além disso, afeta o exercício da profissão. Não é possível manter para esse profissional um padrão de jornada de trabalho diurno e de cinco dias por semana.

Pelos motivos até agora apontados, o mercado de trabalho do setor saúde deve ser considerado como um segmento particular. Sua regulamentação atual constitui uma característica peculiar ao processo de organização da atividade setorial. A definição das profissões que ele abrange (e as suas qualificações específicas) depende das características que lhe são inerentes.

A maior ou menor mercantilização do setor pode, muitas vezes, induzir reduções dos custos incorridos na prestação dos diversos serviços. As regulamentações das profissões e dos procedimentos básicos de organização da atividade buscam conter esse movimento. É por esse motivo que o mercado de trabalho para as profissões do setor saúde não pode ser deixado ao sabor dos mecanismos exclusivos de contratação que caracterizam o mercado de trabalho mais geral. Caso predominem os mecanismos exclusivos de mercado, é provável a ocorrência de perda de qualificação das profissões e de redução dos procedimentos básicos para a realização da atividade.

Aqui se encontra mais um motivo para que o mercado de trabalho do setor saúde seja um mercado específico, particularidade que exige sistemática e estrita regulamentação pública. As qualificações requeridas para as profissões exercidas neste segmento dependem exclusivamente destas e não 
do entendimento que as partes contratantes possam alcançar no estabelecimento do contrato de trabalho.

\section{Sobre a metodologia}

Qualquer discussão sobre a dimensão ocupacional do setor de atendimento à saúde deve tomar como ponto de partida a mensuração do trabalho no setor. Isto é, dar alguma resposta à pergunta: qual é o volume de pessoas ocupadas em atividades vinculadas, direta e indiretamente, ao atendimento do setor saúde?

Para responder a essa questão, deve-se adotar uma metodologia que circunscreva a dimensão setorial e os postos de trabalho aí reproduzidos. Inicialmente, cabe reconhecer que tal metodologia deve ir além da identificação das ocupações vinculadas às profissões específicas, visto que as atividades de saúde mobilizam um conjunto mais amplo de pessoas, por exemplo, o motorista de ambulância, o guarda de um posto de saúde ou o torneiro mecânico de uma metalúrgica especializada na produção de instrumentos cirúrgicos.

Reconhece-se então, que os efeitos de geração de emprego do setor saúde são suficientemente amplos para extrapolar os setores vinculados às atividades-fim. Por isso, duas dimensões básicas, pelo menos, devem ser levadas em conta na mensuração do trabalho no setor saúde: a ocupacional e a setorial. Neste artigo, apresenta-se uma metodologia que parte dessas duas dimensões.

Do ponto de vista setorial, propõe-se a seguinte segmentação das atividades econômicas: fundamentais, complementares, de apoio e, isoladamente, a administração pública, conforme a relação mais ou menos direta com os serviços de atenção à saúde. Dado que a base de dados referencial para a análise é o Censo Demográfico de 2000, do IBGE (CD 2000), utilizou-se sua classificação de setores de atividades, isto é, a Classificação Nacional de Atividades Econômicas - Domiciliar (CNAE-Dom). A partir dessa classificação, foi estabelecida a segmentação setorial de atividades (Quadrol). 


\section{Quadro 1}

Setores da saúde, a partir dos códigos da CNAE-Dom

\begin{tabular}{|c|c|c|}
\hline & Códigos CNAE-Dom & Denominações \\
\hline \multirow[t]{3}{*}{ Atividades fundamentais } & 85011 & Saúde pública \\
\hline & 85012 & Saúde particular \\
\hline & 85013 & Outras atividades de saúde \\
\hline \multirow[t]{3}{*}{ Administração pública } & 75011 & $\begin{array}{l}\text { Administração do Estado e da política } \\
\text { econômica e social - federal }\end{array}$ \\
\hline & 75012 & $\begin{array}{l}\text { Administração do Estado e da política } \\
\text { econômica e social - estadual }\end{array}$ \\
\hline & 75013 & $\begin{array}{l}\text { Administração do Estado e da política } \\
\text { econômica e social - municipal }\end{array}$ \\
\hline \multirow[t]{3}{*}{ Atividades complementares } & 75020 & Seguridade social \\
\hline & 80011 & Educação regular, supletiva e especial pública \\
\hline & 80012 & Educação regular, supletiva e especial privada \\
\hline \multirow[t]{7}{*}{ Atividades de apoio } & 24020 & Fabricação de produtos farmacêuticos \\
\hline & 33001 & $\begin{array}{l}\text { Fabricação de aparelhos e equipamentos } \\
\text { médico-hospitalares }\end{array}$ \\
\hline & 53063 & $\begin{array}{l}\text { Comércio de produtos farmacêuticos, } \\
\text { médicos, ortopédicos, odontológicos e } \\
\text { de cosméticos e perfumaria. }\end{array}$ \\
\hline & 66000 & Seguros e previdência privada \\
\hline & 67020 & $\begin{array}{l}\text { Atividades auxiliares dos seguros e } \\
\text { da previdência privada }\end{array}$ \\
\hline & 71030 & Aluguel de objetos pessoais e domésticos \\
\hline & 85030 & Serviços sociais \\
\hline Demais & - & Demais atividades econômicas \\
\hline
\end{tabular}

Fonte: IBGE - Censo Demográfico 2000

Nota: Dados trabalhados pelos autores.

As ocupações foram classificadas em três grupos: nucleares, afins e demais, também conforme sua relação mais ou menos direta com as atividades de atenção à saúde. Utilizou-se também a Classificação Brasileira de Ocupações — Domiciliar (CBO-Dom), adotada no CD 2000 (Quadro 2). 
Quadro 2

\begin{tabular}{|c|c|c|}
\hline & Códigos CBO-Dom & Descrição \\
\hline \multirow[t]{8}{*}{ Nucleares } & 2231 & Médicos \\
\hline & 2232 & Cirurgiões-dentistas \\
\hline & 2235 & Enfermeiros (nível superior) \\
\hline & 3222 & Auxiliares de enfermagem (nível técnico) \\
\hline & 5151,5152 & $\begin{array}{l}\text { Auxiliares de enfermagem prática (não } \\
\text { diplomados) e auxiliares de laboratório }\end{array}$ \\
\hline & 2515 & Psicólogos \\
\hline & 2236 & $\begin{array}{l}\text { Terapeutas (fisioterapeutas e fonoaudiólogos) } \\
\text { e trabalhos assemelhados de nível superior }\end{array}$ \\
\hline & $3225,3224,3221$ & $\begin{array}{l}\text { Acupunturistas, técnicos em ortopedia, } \\
\text { fisioterapia, protéticos e assemelhados }\end{array}$ \\
\hline \multirow[t]{5}{*}{ Afins } & 2211,2234 & $\begin{array}{l}\text { Biologistas, bacteriologistas } \\
\text { e trabalhos assemelhados, farmacêuticos } \\
\text { e farmacologistas }\end{array}$ \\
\hline & 2237 & Nutricionistas e trabalhos assemelhados \\
\hline & 2516 & Assistentes sociais e economistas domésticos \\
\hline & 3223 & Ortoptistas e ópticos \\
\hline & 3241 & $\begin{array}{l}\text { Operadores de equipamentos médicos } \\
\text { e odontológicos }\end{array}$ \\
\hline Demais & - & Demais ocupações \\
\hline
\end{tabular}

Fonte: IBGE - Censo Demográfico 2002

Notas: (1) Dados trabalhados pelos autores;

(2) A coluna "Descrição" foi formulada pelos autores, segundo a descrição das ocupações mais freqüentes em cada código de quatro dígitos.

Com relação ao grupo das demais ocupações, é importante explicitar que, tanto para a administração pública como para as atividades complementares, foi necessário realizar um ajuste nos números totais. Tal ajuste visou a estimar a geração de ocupação (e renda) induzida pelo setor saúde nestes grupos de atividade.

No tocante ao ajuste do volume das demais ocupações, os critérios adotados foram os seguintes: a) para as atividades de administração pública, dentro do grupo das demais, foram estimadas como ocupações induzidas pelo setor saúde aquelas cuja proporção era idêntica à verificada nos setores fundamentais; ou seja, a mesma relação demais/(afins + nucleares) encontrada para o grupo de atividades fundamentais foi aplicada sobre o total de ocupações afins e nucleares da administração pública, para estimar o volume das demais ocupações neste mesmo setor induzido pelo setor saúde; a diferença entre este volume estimado (corrigido) e o original foi incorporada às demais ocupações pertencentes ao grupo dos demais setores; e b) para as atividades complementares, foi realizado o mesmo ajuste. 
Por fim, conforme pode ser visualizado no Diagrama 1, a metodologia adotada permite mensurar a geração de ocupação no setor de saúde a partir de dois níveis: setor saúde nuclear e setor saúde expandido. O primeiro é composto pelas atividades econômicas e ocupações mais direta e tradicionalmente identificadas com o setor saúde; o segundo nível sintetiza o esforço de mensurar as atividades e as ocupações derivadas dos serviços de atenção à saúde.

\section{Diagrama 1}

Matriz-síntese da composição do setor saúde

Emprego formal no setor saúde (Brasil - 2000)

Setores
Fundamentais

Nota: procedimento para correção das demais ocupações pertencentes aos setores da administração pública e de complementares: a) administração pública: relação demais/(núcleo + afins) dos setores fundamentais; b) complementares: relação demais/(núcleo + afins) das atividades hospitalares. A parte restante das demais ocupações (dos setores administração pública e complementares) foi adicionada às demais ocupações dos demais setores.

Como o objetivo deste trabalho é discutir as características do emprego gerado na área de saúde da forma mais ampla possível, faz-se necessário, ainda com relação à metodologia, mostrar como é possível compatibilizar os dados do CD 2000 com a base Relação Anual de Informações Sociais (Rais). Este esforço de utilização conjunta do cadastro Rais e das informações do CD 2000 tende a ampliar consideravelmente, pelo menos para o conjunto de trabalhadores formais, as possibilidades analíticas, visto que a Rais fornece informações detalhadas da natureza do vínculo empregatício, tais como horas trabalhadas, remuneração média e tipo de contrato. Ou seja, o CD 2000 permite estimar a dimensão ocupacional do setor saúde, enquanto a Rais possibilita o conhecimento da sua extensão do ponto de vista do emprego assalariado formal. 
Correspondência entre CBO-Dom (CD 2000) e CBO (Rais)

\begin{tabular}{|c|c|c|c|c|}
\hline & $\begin{array}{l}\text { Códigos CBO-Dom } \\
\text { (CD 2000) }\end{array}$ & Descrição & $\begin{array}{l}\text { Códigos CBO } \\
\text { (Rais) }\end{array}$ & Descrição \\
\hline \multirow{18}{*}{ Nucleares } & 2231 & Médicos & 06105 a 06190 & Médicos \\
\hline & 2232 & Cirurgiões-dentistas & 06310 a 06390 & Cirurgiões-dentistas \\
\hline & 2235 & Enfermeiros (nível superior) & 07110 a 07190 & Enfermeiros \\
\hline & 2515 & Psicólogos & 07410 a 07490 & Psicólogos \\
\hline & 2236 & Terapeutas (fisio e fono) e trabalhos & 07620 a 07690 & Terapeutas \\
\hline & & assemelhados de nível superior & e 07925 & \\
\hline & 3222 & $\begin{array}{l}\text { Auxiliares de enfermagem } \\
\text { (nível técnico) }\end{array}$ & 07210 a 07290 & $\begin{array}{l}\text { Técnicos de enfermagem e trabalhos } \\
\text { assemelhados (exceto enfermeiros } \\
\text { diplomados) }\end{array}$ \\
\hline & 5151 e 5152 & $\begin{array}{l}\text { Auxiliares de enfermagem prática (não } \\
\text { diplomados) e auxiliares de laboratório }\end{array}$ & $\begin{array}{l}57210 \text { a } 57290 \\
\text { e } 07915 \text { a } 07950 \\
\text { exceto } 07925\end{array}$ & $\begin{array}{l}\text { Pessoal de enfermagem, parteiras, } \\
\text { laboratórios e trabalhos assemelhados }\end{array}$ \\
\hline & 3224 & Técnicos de odontologia & 84250 & Protéticos \\
\hline & 3221 & Técnicos em fisioterapia e afins & $\operatorname{scd} *$ & - \\
\hline & 3242 & $\begin{array}{l}\text { Técnicos de laboratório } \\
\text { e análises clínicas }\end{array}$ & 03140 e 03145 & $\begin{array}{l}\text { Técnicos de laboratório e } \\
\text { laboratoristas }\end{array}$ \\
\hline & 3251 & Técnicos em farmácia & 03650 & Técnicos em farmácia \\
\hline & 3522 & Agentes de saúde e de meio ambiente & 31920 & Agente de saúde pública \\
\hline & 5102 & $\begin{array}{l}\text { Supervisores dos serviços de saúde } \\
\text { e cuidados pessoais }\end{array}$ & $\mathrm{scd}^{*}$ & - \\
\hline & 2234 & Farmacêuticos e farmacologistas & 06710 a 06790 & Farmacêuticos \\
\hline & 2237 & Nutricionistas e trabalhos assemelhados & 06810 a 06890 & Nutricionistas e dietistas \\
\hline & 3223 & Ortoptistas e ópticos & 07525 a 07590 & $\begin{array}{l}\text { Ópticos, ortoptistas e trabalhos } \\
\text { assemelhados }\end{array}$ \\
\hline & 3241 & $\begin{array}{l}\text { Operadores de equipamentos } \\
\text { médicos e odontológicos }\end{array}$ & 07720 a 07790 & $\begin{array}{l}\text { Operadores de equipamentos } \\
\text { médicos e odontológicos }\end{array}$ \\
\hline \multirow{10}{*}{ Afins } & 2211 & $\begin{array}{l}\text { Biologistas, bacteriologistas } \\
\text { e trabalhos assemelhados }\end{array}$ & $\begin{array}{l}05110 \text { e } 05140 \\
\text { a } 05290\end{array}$ & Biologistas e trabalhos assemelhados \\
\hline & 2516 & $\begin{array}{l}\text { Assistentes sociais e } \\
\text { economistas domésticos }\end{array}$ & 07310 a 07390 & Assistentes sociais \\
\hline & 2131 & Físicos & 01215 & Físico (medicina) \\
\hline & 3012 & Técnicos de apoio à bioengenharia & $\mathrm{scd} *$ & - \\
\hline & 3201 & Técnicos em biologia & 03190 & $\begin{array}{l}\text { Técnicos de biologia, agronomia } \\
\text { e trabalhos assemelhados }\end{array}$ \\
\hline & 3253 & Técnicos de apoio à biotecnologia & & \\
\hline & 5162 & $\begin{array}{l}\text { Atendentes de creches e } \\
\text { acompanhantes de idosos }\end{array}$ & $\mathrm{scd} *$ & - \\
\hline & 8103 & $\begin{array}{l}\text { Supervisores de indústria } \\
\text { farmacêutica e afins }\end{array}$ & & \\
\hline & 8118 & $\begin{array}{l}\text { Operadores de máquinas de prod.e } \\
\text { inst. farmac. e afins }\end{array}$ & 74250 & $\begin{array}{l}\text { Operadores de autoclave } \\
\text { (tratamentos químicos e afins) }\end{array}$ \\
\hline & 9153 & $\begin{array}{l}\text { Rep. de equipamentos e instrumentos } \\
\text { médico-hospitalares }\end{array}$ & 84245 & Rep. de equip ortopédicos \\
\hline
\end{tabular}

Fontes: IBGE - Censo Demográfico 2000 e MTE - Rais 2001.

Nota: Dados trabalhados pelos autores.

* scd = sem correspondência direta entre os códigos. 
Inicialmente, a partir das mudanças da codificação do CD 2000, acreditou-se que a criação da CNAE-Dom e da CBO-Dom iria tornar tais codificações próximas das utilizadas pela Rais. No entanto, na prática isso não ocorreu.

O Quadro 3 revela, mas não abarca todas as dificuldades encontradas para a compatibilização entre a estrutura de classificação de ocupações utilizada pela Rais (CBO) e aquela utilizada pelo CD 2000 (CBO-Dom).

A partir do Quadro 3, pode-se observar que o fato de a codificação das ocupações da Rais ser apresentada com cinco dígitos permite uma precisão bem maior que a do Censo Demográfico, cuja codificação é feita a quatro dígitos. No entanto, no caso das ocupações para área de saúde, tal fato não representa um entrave para a compatibilização, visto que não há muitas dificuldades em identificar as ocupações que são consideradas nucleares do setor, tais como médicos, enfermeiros (diplomados ou não) e dentistas, tampouco as ocupações que devem ser consideradas afins, como biologistas, nutricionistas, operadores de equipamentos médicos, bacteriologistas e farmacologistas.

A outra etapa da compatibilização diz respeito aos setores de atividade que compõem a matriz. Ao contrário da estrutura de ocupações, cabe mencionar que há consideráveis obstáculos à comparação direta dos setores de atividade econômica entre o CD 2000 e a Rais. Estes obstáculos são encontrados devido à adoção de diferentes classificações: enquanto na Rais é usada a CNAE (Classificação Nacional das Atividades Econômicas), no Censo 2000 usa-se a CNAE-Dom (CNAE Domiciliar).

Apesar das suas denominações — que sugerem uma larga similitude entre ambas - , estas classificações não apresentam uma correspondência direta e inequívoca. De fato, são diferentes os critérios que pautam as divisões e subdivisões de códigos da CNAE e da CNAE-Dom, razão pela qual a Comissão Nacional de Classificações (Concla), do IBGE, elaborou uma tabela de correspondência entre ambas.

É preciso mencionar, porém, que as diferentes lógicas de construção implicam uma comparabilidade limitada quando, como no presente projeto, deseja-se fazer uma seleção de setores de atividade para estudo de um segmento econômico amplo que envolve vários códigos.

O Quadro 4 sistematiza as soluções propostas para o estudo do setor saúde, a partir da tabela de correspondência da Concla proposta pelo IBGE. 
Compatibilização final dos setores de saúde, considerando CNAE-Dom (CD 2000) e CNAE (Rais)

\begin{tabular}{|c|c|c|c|}
\hline & $\begin{array}{l}\text { Códigos CNAE-Dom } \\
\text { (CD 2000) }\end{array}$ & $\begin{array}{l}\text { Códigos CNAE } \\
\text { (Rais) }\end{array}$ & Descrição \\
\hline \multirow[t]{6}{*}{ Atividades fundamentais } & 85011,85012 & $85.11-1$ & Atividades de atendimento hospitalar \\
\hline & & $85.12-0$ & Atividades de atendimento a urgências e emergências \\
\hline & & $85.13-8$ & Atividades de atenção ambulatorial \\
\hline & & $85.14-6$ & $\begin{array}{l}\text { Atividades de serviços de complementação diagnóstica } \\
\text { ou terapêutica }\end{array}$ \\
\hline & & $85.15-4$ & Atividades de outros profissionais da área de saúde \\
\hline & 85013 & $85.16-2$ & Outras atividades relacionadas com a atenção à saúde \\
\hline \multirow[t]{3}{*}{ Administração pública } & 75011 & & \\
\hline & 75012 & 75.11-6 & Administração pública em geral \\
\hline & 75013 & & \\
\hline Atividades & 75020 & $75.30-2$ & Seguridade social \\
\hline \multirow[t]{2}{*}{ complementares } & 80011 & $80.30-6$ & Educação superior \\
\hline & 80012 & & \\
\hline \multirow[t]{11}{*}{ Atividades de apoio } & 24020 & $24.51-1$ & Fabricação de produtos farmoquímicos \\
\hline & & $24.52-0$ & Fabricação de medicamentos para uso humano \\
\hline & & $24.54-6$ & $\begin{array}{l}\text { Fabricação de materiais para uso médico, hospitalar } \\
\text { e odontológico }\end{array}$ \\
\hline & 33001 & $33.10-3$ & $\begin{array}{l}\text { Fabricação de aparelhos e instrumentos para uso } \\
\text { médico-hospitalar, odontológico e de laboratório e } \\
\text { aparelhos ortopédicos }\end{array}$ \\
\hline & 53063 & $51.45-4$ & $\begin{array}{l}\text { Comércio atacadista de produtos farmacêuticos, médicos, } \\
\text { ortopédicos e odontológicos }\end{array}$ \\
\hline & & $52.41-8$ & $\begin{array}{l}\text { Comércio varejista de produtos farmacêuticos, artigos } \\
\text { médicos e ortopédicos, de perfumaria e cosméticos }\end{array}$ \\
\hline & 66000 & $66.30-3$ & Planos de saúde \\
\hline & 67020 & $67.20-2$ & Atividades auxiliares dos seguros e da previdência privada \\
\hline & 71030 & $71.40-4$ & Aluguel de objetos pessoais e domésticos \\
\hline & 85030 & $85.31-6$ & Serviços sociais com alojamento \\
\hline & & $85.32-4$ & Serviços sociais sem alojamento \\
\hline
\end{tabular}

Fonte: IBGE - Concla

Nota: Dados trabalhados pelos autores.

Conforme apresentado no Quadro 4, pode-se notar que, dentre os setores de atividade econômica que integram o setor de atendimento à saúde classificado como 'fundamentais', a divisão do prefixo 850 na CNAE-Dom (CD 2000) obedece ao critério saúde pública versus privada. Ao passo que, na CNAE (Rais), a divisão do prefixo correspondente 85 relaciona-se à identificação mais detalhada de cada uma das atividades de atenção direta à saúde, independentemente de situar-se na esfera pública ou privada.

O mesmo tipo de dificuldade pode ser observado no tocante ao grupo 'administração pública', uma vez que, na CNAE-Dom, o prefixo 750 é subdi- 
vidido nas três esferas do Estado (federal, estadual e municipal), enquanto o seu correspondente na CNAE - prefixo 75 - apresenta subcódigos que especificam em detalhe diferentes atividades da administração pública.

Contudo, como o presente estudo tem como objetivo analisar as categorias de setores e não comparar atividade a atividade, a solução proposta para agregação não inviabiliza a comparabilidade das bases de dados, como será visto a seguir.

\section{Alguns resultados}

Neste item, serão apresentados alguns resultados gerais obtidos com a implementação da metodologia descrita nas bases de informação do CD 2000 e Rais.

A Tabela 1 fornece a estimativa do emprego gerado pelas atividades de atenção à saúde. Para o total do Brasil, em 2000, aproximadamente 4,2\% da população ocupada estava envolvida em atividades direta ou indiretamente ligadas ao setor e um pouco mais da metade desse percentual pertencia ao chamado núcleo das atividades de saúde.

Tabela 1

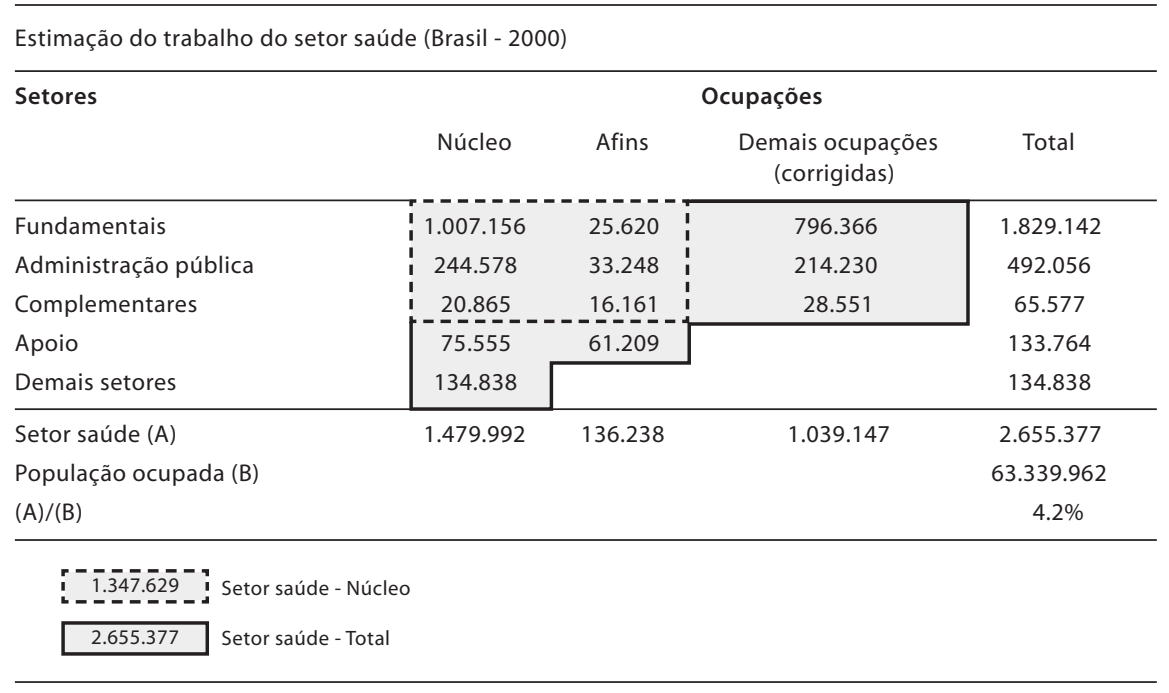

Fonte: IBGE - Censo Demográfico 2000

Nota: (1) Dados trabalhados pelo Projeto Saúde-Emprego, MS-IE/Unicamp.

(2) procedimento para correção das demais ocupações pertencentes aos setores da administração pública e de complementares: a) administração pública: relação demais/(núcleo + afins) dos setores fundamentais; b) complementares: relação demais/(núcleo + afins) das atividades hospitalares. A parte restante das demais ocupações (dos setores administração pública e complementares) foi adicionada às demais ocupações dos demais setores. 
Os dados da Rais (Tabela 2) para o Brasil naquele mesmo ano permitem estimar 1,9 milhão de pessoas empregadas formalmente para o conjunto do setor. Isto é, a comparação dos resultados revela que ao menos $72 \%$ dos ocupados do setor saúde eram assalariados formais, média bastante superior à encontrada para o conjunto do nosso mercado de trabalho.

Em contrapartida, a comparação mostra uma participação relativamente menor das ocupações nucleares na Rais, frente ao encontrado no censo demográfico. Mesmo assim, os dados revelam que a política de saúde pode cumprir uma função social que extrapola seu objetivo-fim: a melhora do bem-estar da população. Ela tem, ademais, capacidade de gerar empregos em volume ponderável tanto nas atividades nucleares como nas atividades afins e de apoio, bem como de indução do emprego formal.

Tabela 2

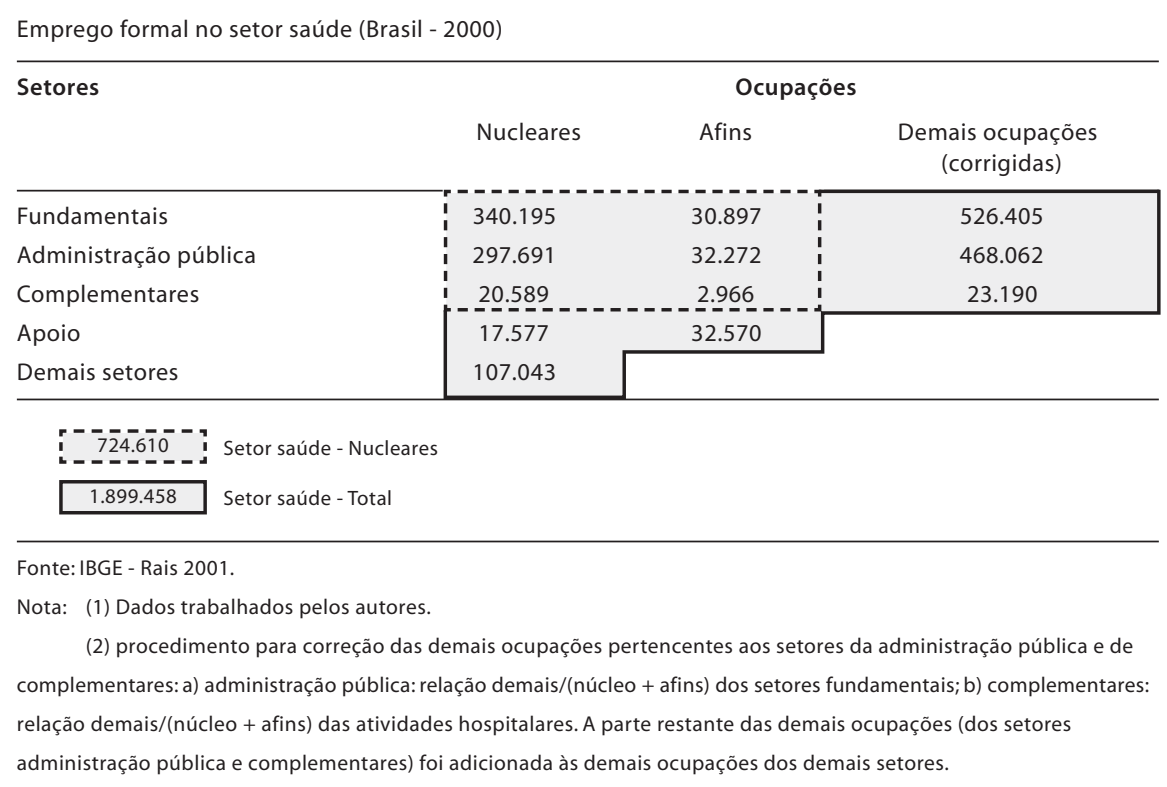

Um outro dado que chama atenção é que, comparativamente aos médicos, o pessoal de enfermagem apresenta um elevado grau de inserção com carteira de trabalho assinada e no emprego público (Tabela 3). Isto quer dizer que mais de $80 \%$ das pessoas que exercem a função de enfermagem apresentam um vínculo formal de trabalho (tal percentual chega a $87 \%$ para o pessoal de enfermagem de nível superior), ao passo que, entre os médicos, há uma elevada participação de empregadores e 'conta-própria' (ou autônomos). 
Tabela 3

Principais ocupações na saúde segundo posição na ocupação (Brasil - 2000)

\begin{tabular}{|c|c|c|c|c|}
\hline Posição na ocupação & Médicos & Enfermeiros & $\begin{array}{l}\text { Auxiliares e técnicos } \\
\text { de enfermagem }\end{array}$ & $\begin{array}{l}\text { Atendentes de } \\
\text { enfermagem } \\
\text { (não diplomados) }\end{array}$ \\
\hline Empregado com carteira de trabalho assinada & $33 \%$ & $64 \%$ & $66 \%$ & $62 \%$ \\
\hline $\begin{array}{l}\text { Empregado pelo Regime Jurídico de Pessoa Física } \\
\text { (estatutário) ou como militar }\end{array}$ & $14 \%$ & $24 \%$ & $18 \%$ & $19 \%$ \\
\hline Empregado sem carteira de trabalho assinada * & $12 \%$ & $9 \%$ & $10 \%$ & $15 \%$ \\
\hline Empregador & $11 \%$ & $0 \%$ & - & - \\
\hline Conta-própria & $28 \%$ & $3 \%$ & $4 \%$ & - \\
\hline Aprendiz ou estagiário sem remuneração & $1 \%$ & $0 \%$ & $2 \%$ & $3 \%$ \\
\hline Não remunerado em ajuda a membro do domicílio & - & - & $0 \%$ & $0 \%$ \\
\hline Total & 198.153 & 54.064 & 422.583 & 214.122 \\
\hline
\end{tabular}

Fonte: IBGE - Censo Demográfico 2000

* Sem CLT, não estatutário nem militar.

Tabela 4

Número de trabalhos nas ocupações do setor saúde segundo posição na ocupação (Brasil - 2000)

\begin{tabular}{|c|c|c|c|c|c|c|c|c|}
\hline \multirow[t]{2}{*}{ Posição na ocupação } & \multicolumn{2}{|c|}{ Médicos } & \multicolumn{2}{|c|}{ Enfermeiros } & \multicolumn{2}{|c|}{$\begin{array}{c}\text { Auxiliares e técnicos } \\
\text { de enfermagem }\end{array}$} & \multicolumn{2}{|c|}{$\begin{array}{l}\text { Atendentes de enfermagem } \\
\text { (não diplomados) }\end{array}$} \\
\hline & Um & $\begin{array}{c}\text { Dois ou } \\
\text { mais }\end{array}$ & Um & $\begin{array}{c}\text { Dois ou } \\
\text { mais }\end{array}$ & Um & $\begin{array}{c}\text { Dois ou } \\
\text { mais }\end{array}$ & Um & $\begin{array}{c}\text { Dois ou } \\
\text { mais }\end{array}$ \\
\hline $\begin{array}{l}\text { Empregado com carteira de } \\
\text { trabalho assinada }\end{array}$ & 28.651 & 36.836 & 26.320 & 8.075 & 243.822 & 36.483 & 120.938 & 11.143 \\
\hline $\begin{array}{l}\text { Empregado pelo Regime Jurídico de } \\
\text { Pessoa Física (estatutário) ou como milita }\end{array}$ & 12.115 & 15.985 & 9.686 & 3.404 & 69.120 & 8.861 & 38.375 & 3.365 \\
\hline $\begin{array}{l}\text { Empregado sem carteira de } \\
\text { trabalho assinada * }\end{array}$ & 13.908 & 9.954 & 3.908 & 874 & 38.617 & 3.313 & 30.467 & 1.838 \\
\hline Empregador & 12.318 & 10.098 & 109 & 0 & 0 & 0 & 0 & 0 \\
\hline Conta-própria & 32.196 & 23.781 & 1.322 & 262 & 14.052 & 1.313 & 0 & 0 \\
\hline Aprendiz ou estagiário sem remuneração & 2.012 & 298 & 73 & 0 & 6.291 & 237 & 6.911 & 318 \\
\hline $\begin{array}{l}\text { Não remunerado em ajuda a membro } \\
\text { do domicílio }\end{array}$ & 0 & 0 & 0 & 0 & 292 & 10 & 649 & 16 \\
\hline Total & 101.201 & 96.952 & 41.439 & 12.626 & 372.192 & 50.218 & 197.340 & 16.680 \\
\hline
\end{tabular}

Fonte: IBGE - Censo Demográfico 2000

Nota: Dados trabalhados pelos autores.

* Sem CLT, não estatutário nem militar. 
Essa situação é reproduzida quando se analisa a inserção ocupacional segundo o número de trabalhos. Infelizmente, o CD 2000 só permite avaliar o exercício de um ou mais trabalhos, não havendo possibilidade de se especificar, quando existente, o número de ocorrências (ver Tabela 4).

Dentre os médicos, cerca de metade declararam possuir dois ou mais vínculos. Ademais, 55\% dos que possuem carteira de trabalho assinada ou são servidores públicos que afirmaram ter mais de um vínculo empregatício. Contudo, apenas 12\% do pessoal de enfermagem informaram ter mais de um vínculo (ver Tabela 4).

A situação diferenciada entre médicos e pessoal de enfermagem, quanto à existência de mais de um trabalho, deve ser resultante, provavelmente, da natureza do vínculo empregatício, em especial dos médicos, que tendem a estabelecer contratos adicionais com uma jornada de trabalho 24 horas, correspondente ao plantão. Ao contrário do pessoal de enfermagem para quem esta opção não está disponível.

Com o intuito de compreender melhor a composição da estrutura ocupacional dentre as ocupações nucleares do setor de atendimento à saúde, abandona-se aqui a análise para o conjunto do país e adota-se o recorte regional para o estado de São Paulo. Isto é, exploram-se as informações para o mercado de trabalho considerado com menor grau de precariedade do país e que responde por cerca de $25 \%$ das principais ocupações nucleares do setor de atendimento à saúde brasileiro: médicos, profissionais da área de enfermagem e agentes de saúde.

A análise da estrutura ocupacional (Tabela 5) mostra, em primeiro lugar, a menor incidência da jornada adicional de trabalho para todas as ocupações do pessoal de enfermagem. Enquanto os médicos realizavam uma jornada semanal no trabalho principal de 39 horas e no trabalho adicional, de 13 horas, os enfermeiros de nível superior exerciam, respectivamente, jornadas de 40 horas e cinco horas. A possibilidade de jornada adicional decresce para o pessoal de enfermagem de menor qualificação.

Também é substantiva a diferença salarial entre médicos e enfermeiros de nível superior, tanto no trabalho principal como no secundário. Os médicos ganham mais de 2,5 vezes no trabalho principal que os enfermeiros de nível superior. Mesmo quando circunscrita ao servidor público, essa diferença continua sendo ponderável (aproximadamente duas vezes). 
Tabela 5

Rendimentos e horas trabalhadas, no trabalho principal e nos demais trabalhos, nas ocupações do setor saúde, segundo posição na ocupação (São Paulo - 2000)

\begin{tabular}{|c|c|c|c|c|}
\hline & Médicos & Enfermeiros & $\begin{array}{l}\text { Auxiliares e } \\
\text { técnicos de } \\
\text { enfermagem }\end{array}$ & $\begin{array}{l}\text { Atendentes de } \\
\text { enfermagem } \\
\text { (não diplomados) }\end{array}$ \\
\hline \multicolumn{5}{|l|}{ Empregado com carteira de trabalho assinada } \\
\hline Rendimento bruto no trabalho principal & $3.305,58$ & $1.610,46$ & 736,01 & 573,94 \\
\hline Rendimento bruto nos demais trabalhos & $2.493,88$ & $1.129,89$ & 621,80 & 492,01 \\
\hline Horas trabalhadas por semana no trabalho principal & 39 & 40 & 42 & 42 \\
\hline Horas trabalhadas nos demais trabalhos & 13 & 5 & 4 & 2 \\
\hline \multicolumn{5}{|l|}{$\begin{array}{l}\text { Empregado pelo Regime Jurídico de Pessoa Física } \\
\text { (estatutário) ou como militar }\end{array}$} \\
\hline Rendimento bruto no trabalho principal & $2.813,00$ & $1.518,00$ & 730,00 & 647,00 \\
\hline Rendimento bruto nos demais trabalhos & $2.292,00$ & $1.239,00$ & 620,00 & 562,00 \\
\hline Horas trabalhadas por semana no trabalho principal & 38 & 37 & 38 & 36 \\
\hline Horas trabalhadas nos demais trabalhos & 14 & 7 & 3 & 2 \\
\hline \multicolumn{5}{|l|}{ Empregado sem carteira de trabalho assinada * } \\
\hline Rendimento bruto no trabalho principal & $2.648,64$ & $1.358,95$ & 630,11 & 454,60 \\
\hline Rendimento bruto nos demais trabalhos & $2.131,42$ & $1.380,00$ & 510,05 & 432,75 \\
\hline Horas trabalhadas por semana no trabalho principal & 46 & 40 & 44 & 42 \\
\hline Horas trabalhadas nos demais trabalhos & 9 & 4 & 2 & 1 \\
\hline \multicolumn{5}{|l|}{ Empregador } \\
\hline Rendimento bruto no trabalho principal & $7.171,02$ & $1.527,00$ & - & - \\
\hline Rendimento bruto nos demais trabalhos & $3.229,88$ & - & - & - \\
\hline Horas trabalhadas por semana no trabalho principal & 42 & 43 & - & - \\
\hline Horas trabalhadas nos demais trabalhos & 10 & - & - & - \\
\hline \multicolumn{5}{|l|}{ Conta-própria } \\
\hline Rendimento bruto no trabalho principal & 5.047 & 1.536 & 868 & - \\
\hline Rendimento bruto nos demais trabalhos & 2.493 & 980 & 590 & - \\
\hline Horas trabalhadas por semana no trabalho principal & 43 & 39 & 45 & - \\
\hline Horas trabalhadas nos demais trabalhos & 9 & 4 & 2 & - \\
\hline \multicolumn{5}{|l|}{ TOTAL } \\
\hline Rendimento bruto no trabalho principal & $4.165,05$ & $1.585,51$ & 735,00 & 573,12 \\
\hline Rendimento bruto nos demais trabalhos & $2.499,69$ & $1.153,14$ & 615,15 & 523,66 \\
\hline Horas trabalhadas por semana no trabalho principal & 42 & 40 & 42 & 41 \\
\hline Horas trabalhadas nos demais trabalhos & 11 & 5 & 4 & 2 \\
\hline
\end{tabular}

Fonte: IBGE - Censo Demográfico 2000

* Sem CLT, não estatutário nem militar. 
A diferenciação salarial, considerada a possibilidade do trabalho adicional, sugere uma forte diferenciação (valorização) entre as carreiras de médicos e de enfermeiros de nível superior no mercado específico de trabalho, provavelmente induzida pela própria política pública de saúde. A recorrência de uma remuneração relativamente baixa para o pessoal de enfermagem alcança todas as suas ocupações.

Um outro aspecto importante sobre o padrão de remuneração é sua relação com o número de trabalhos. Para ter maior controle do resultado, explorou-se somente as informações das ocupações nucleares da base de informações Rais de 2001 para o estado de São Paulo (Tabela 6). Ainda com essa mesma preocupação, foi adotada uma padronização da remuneração para uma jornada de trabalho de 24 horas, correspondente à adotada no regime de plantão.

Tabela 6

\begin{tabular}{|c|c|c|c|c|c|c|c|c|c|c|}
\hline \multirow{2}{*}{$\begin{array}{l}\text { Número de } \\
\text { vínculos por } \\
\text { indivíduo }\end{array}$} & \multicolumn{2}{|c|}{ Médicos } & \multicolumn{2}{|c|}{ Enfermeiros } & \multicolumn{2}{|c|}{$\begin{array}{l}\text { Técnicos em } \\
\text { enfermagem }\end{array}$} & \multicolumn{2}{|c|}{$\begin{array}{l}\text { Auxiliares de } \\
\text { enfermagem }\end{array}$} & \multicolumn{2}{|c|}{$\begin{array}{c}\text { Agentes e } \\
\text { visitadores sanitários }\end{array}$} \\
\hline & $\begin{array}{c}\text { Renda média } \\
\text { padrão } 24 \mathrm{~h} \\
\text { (em R\$) }\end{array}$ & $\begin{array}{l}\text { Postos } \\
\text { de } \\
\text { trabalho }\end{array}$ & $\begin{array}{c}\text { Renda média } \\
\text { padrão } 24 \mathrm{~h} \\
\text { (em R\$) }\end{array}$ & $\begin{array}{l}\text { Postos } \\
\text { de } \\
\text { trabalho }\end{array}$ & $\begin{array}{l}\text { Renda média } \\
\text { padrão } 24 \mathrm{~h} \\
\text { (em R\$) }\end{array}$ & $\begin{array}{l}\text { Postos } \\
\text { de } \\
\text { trabalho }\end{array}$ & $\begin{array}{c}\text { Renda média } \\
\text { padrão } 24 \mathrm{~h} \\
\text { (em } \mathrm{R} \$ \text { ) }\end{array}$ & $\begin{array}{l}\text { Postos } \\
\text { de } \\
\text { trabalho }\end{array}$ & $\begin{array}{c}\text { Renda média } \\
\text { padrão } 24 \mathrm{~h} \\
\text { (em R\$) }\end{array}$ & $\begin{array}{l}\text { Postos } \\
\text { de } \\
\text { trabalho }\end{array}$ \\
\hline 1 & $2.429,35$ & 23.905 & $1.253,45$ & 15.721 & 521,11 & 21.024 & 534,22 & 101.454 & 317,48 & 9.018 \\
\hline 2 & $2.255,18$ & 20.540 & $1.151,53$ & 6.788 & 538,13 & 6.968 & 541,36 & 28.484 & 770,03 & 106 \\
\hline 3 & $2.277,41$ & 8.520 & $1.185,39$ & 621 & 534,92 & 330 & 507,26 & 1.277 & $1.063,48$ & 2 \\
\hline 4 & $2.276,55$ & 2.381 & $1.108,19$ & 28 & 662,46 & 4 & 638,49 & 22 & - & - \\
\hline 5 & $2.178,88$ & 520 & - & - & - & - & - & - & - & - \\
\hline 6 & $2.535,80$ & 152 & - & - & - & - & - & - & - & - \\
\hline 7 & $2.709,88$ & 68 & - & - & - & - & - & - & - & - \\
\hline 8 & $2.145,22$ & 15 & - & - & - & - & - & - & - & - \\
\hline Média geral (R\$) & $2.333,21$ & - & $1.221,47$ & - & 525,43 & - & 535,53 & - & 322,89 & - \\
\hline Total & - & 56.193 & - & 23.164 & - & 28.331 & - & 131.284 & - & 9.127 \\
\hline
\end{tabular}

Fonte: MTE - Rais 2001

Nota: Dados trabalhados pelos autores.

Os resultados mostram que o maior número de vínculos é associado a uma tendência de deterioração da remuneração, tanto para médicos como para os enfermeiros de nível superior, não se observando o mesmo para as demais ocupações consideradas. Apesar do número maior de vínculos permitir uma renda total mais alta, constata-se que a remuneração/hora é menor, podendo-se inferir que a busca por um número maior de trabalhos parece estar relacionada à defesa da remuneração total. No entanto, devido às especificidades do contrato de trabalho, tal prática é mais encontrada para os médicos. 


\section{Observações finais}

Este artigo teve por motivação apresentar uma iniciativa de análise do mercado de trabalho específico do setor de atendimento à saúde. Como indicado inicialmente, a dimensão desse mercado é delimitada pelos efeitos diretos e indiretos característicos da atividade, bem como pelos efeitos da extensão dos gastos da política de atendimento à saúde sobre o mercado de trabalho. Logo sua dimensão extrapola sua atividade-fim.

A iniciativa apresentada não contou, em seu início, com uma literatura farta sobre o assunto. Os trabalhos encontrados voltam-se, em sua maioria, para a discussão sobre gestão dos recursos humanos diretamente envolvidos na política de saúde.

Por esse motivo, foi desenvolvida uma metodologia específica aos objetivos da pesquisa, apresentada extensamente nesse artigo. A partir desse procedimento, foi estimado o pessoal ocupado no setor de atendimento à saúde, equivalente a $4,2 \%$ da população ocupada brasileira, bem como dimensionada a grandeza do emprego formal.

Em seguida, foi identificado o nível e a participação da ocupação nuclear na estrutura estimada de ocupação setorial. Com essa informação, foi possível explorar algumas características das ocupações nucleares. Algumas diferenças quanto às características básicas de inserção (número de trabalhos, jornada de trabalho e remuneração) foram analisadas, encontrando-se grandes diferenças entre as ocupações de medicina e enfermagem.

Não foi possível proceder a uma análise mais acurada dessas informações. Entretanto, podem-se identificar algumas tendências/características importantes para aqueles pesquisadores e gestores preocupados com a política de saúde e que vêem no trabalho uma referência relevante para a sua estruturação: 1) os impactos do gasto do setor saúde para a geração de ocupações extrapola a dimensão da sua atividade-fim; 2) é considerável o efeito de geração de ocupações do setor: $4,2 \%$ da população economicamente ativa; 3) há um potencial elevado de formalização dessas ocupações, se comparado com a média do mercado de trabalho brasileiro; 4) as condições básicas de trabalho são bastante diferenciadas entre as ocupações nucleares; 5) a recorrência de mais de um trabalho é específica aos médicos; 6) o maior número de trabalhos tende ser associado a uma menor remuneração/hora.

Essas informações básicas podem ser complementadas por outras que possam melhor fornecer subsídios à gestão da política de atendimento à saúde e, mesmo, à análise de seu gasto. Por exemplo, em 2000, foi aprovada a Emenda Constitucional $n^{\circ} 29$, que vincula os recursos da saúde nas diversas esferas de governo. Uma característica dessa emenda é a preocupação com os impactos do gasto da política para a geração de empregos. 
O artigo identificou a capacidade básica de geração, mas não discutiu como a política organiza esse mercado específico. Encontra-se aberto o debate sobre as implicações da política para a geração de ocupações de melhor qualificação, bem como sobre outras questões relativas à estrutura ocupacional.

Considerando o escopo deste trabalho, não foi possível tratar da diversidade de temas envolvidos na discussão sobre política de saúde e geração de emprego. Entretanto, acredita-se que, com esta reflexão, mostra-se a importância do tema tanto para a discussão da política de saúde quanto para aquela específica sobre o mercado de trabalho brasileiro.

\section{Notas}

1 Professor do Instituto de Economia da Unicamp e Pesquisador do Centro de Estudos Sindicais e de Economia do Trabalho da Universidade Estadual de Campinas (Cesit/Unicamp). Doutor em Economia. <cdedecca@eco.unicamp.br>

2 Professora do CEA/PUC-Campinas e Pesquisadora do Centro de Estudos Sindicais e de Economia do Trabalho da Universidade Estadual de Campinas (Cesit/Unicamp). Doutora em Economia.<elirosan@eco.unicamp.br>

3 Pesquisador do Centro de Estudos Sindicais e de Economia do Trabalho da Universidade Estadual de Campinas (Cesit/Unicamp). Mestre em Economia.

4 Mestranda do Instituto de Economia da Unicamp e Pesquisadora do Centro de Estudos Sindicais e de Economia do Trabalho da Universidade Estadual de Campinas (Cesit/ Unicamp).

5 Este artigo foi elaborado a partir dos resultados de dois projetos realizados no Instituto de Economia e no Núcleo de Estudos em Políticas Públicas da Unicamp, com financiamento do Ministério da Saúde, que trataram do trabalho no setor de atendimento à saúde. Os autores são os únicos responsáveis pelos dados, pelas informações e pelas conclusões apresentadas. 


\section{Referências}

DEDECCA, Cláudio; PRONI, Marcelo W.; MORETO, Amilton. 2001. O trabalho no setor de atendimento à saúde. In: NEGRI, Barjas; GIOVANNI, Geraldo (orgs.). Brasil: radiografia da saúde. Campinas: Instituto de Economia, Unicamp, pp. 175-216.

DEDECCA, Cláudio; ROSANDISKI, Eliane. 2003. Sensos e dissensos: o Censo Demográfico 2000. Revista de Estudos do Trabalho, ano III, n. 2.

ENGEL, Cynthia. 1999. Health services industry: still a job machine? Monthly Labor Review Online, v. 122, n. 3.
NOGUEIRA, Roberto P.; SANTANA, José P. de. 2000. Gestão de recursos humanos e reformas do setor público: tendências e pressupostos de uma nova abordagem. Trabalho apresentado no Workshop on Global Health Workforce Strategy. Annecy, França: OMS.

POZ, Mário D.; PIERANTONI, Célia R.; VARELLA, Thereza C. 1997. Produtividade e desempenho dos recursos humanos nos serviços de saúde. Rio de Janeiro: IMS Uerj/Opas.

Recebido em 23/09/2004

Aprovado em 05/12/2004 